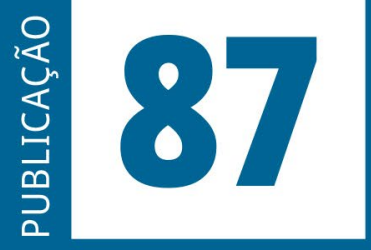

ISSN: 0101-9562

ISSN ELETRÔNICO: 2177-7055

SEQÜENCIA

Publicação do

Programa de Pós-Graduação em Direito da UFSC

VOLUME 42 - ANO 2021
Estudos jurídicos e políticos 
SEQUÊNCIA - ESTUDOS JURÍDICOS E POLÍTICOS é uma publicação temática e de periodicidade quadrimestral, editada pelo Programa de Pós-Graduação Stricto Sensu em Direito da Universidade Federal de Santa Catarina - UFSC.

SEQUÊNCIA - ESTUDOS JURÍDICOS E POLÍTICOS is a thematic publication, printed every four months, edited by the Program in law of the Federal University of Santa Catarina - UFSC.

Versão eletrônica: http://www.periodicos.ufsc.br/index.php/sequencia

A publicação é indexada nas seguintes bases de dados e diretórios/

The Publication is indexed in the following databases and directories:

Base OJS

Base PKP

CCN (Catálogo Coletivo Nacional)

Dialnet

DOAJ (Directory of Open Access Journals)

EBSCOhost

Genamics Journalseek

ICAP (Indexação Compartilhada de Artigos de Periódicos)

Latindex

LivRe!

OJS
PKP
Portal de Periódicos UFSC
Portal do SEER
ProQuest
SciELO
Sherpa/Romeo
Sumarios.org
ULRICH'S
vLex

Ficha catalográfica

Seqüência: Estudos jurídicos e políticos. Universidade Federal de Santa Catarina.

Programa de Pós-Graduação em Direito. n.1 (janeiro 1980)-.

Florianópolis: Fundação José Boiteux. 1980-.

Publicação contínua

Resumo em português e inglês

Versão impressa ISSN 0101-9562

Versão on-line ISSN 2177-7055

1. Ciência jurídica. 2. Teoria política. 3. Filosoia do direito. 4. Periódicos.

I. Universidade Federal de Santa Catarina. Programa de Pós-graduação em

Direito

CDU 34(05)

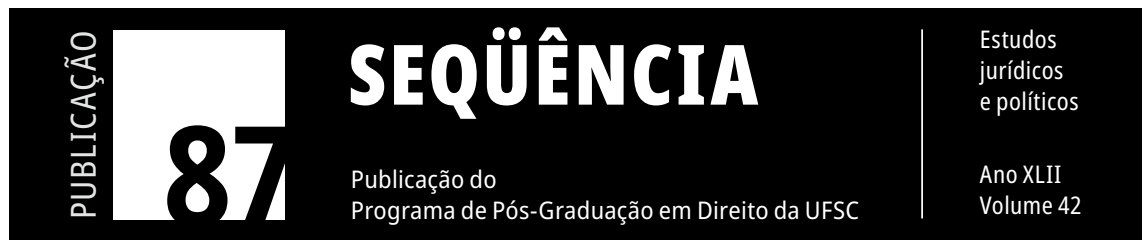




\title{
Administración Pública, agentes públicos y planeación social: Reforzando las perspectivas éticas del Derecho Administrativo para el desafío pandémico
}

\author{
Public administration, public agents \\ and social planning: Strengthening the ethical perspectives \\ of administrative law for the pandemic challenge
}

Lígia Maria Silva Melo de Casimiro

Universidad Federal de Ceará, Fortaleza, Brasil

Álvaro Sanchez Bravo

Universidad de Sevilla, Sevilla, España

RESUMEN: Este artículo defiende la importancia vital de la planificación sistemática para la Administración Pública brasileña, especialmente para los nuevos desafíos planteados por la pandemia del SARS Covid. El análisis incluye una descripción de la historia del uso del instrumento por parte del Estado brasileño antes de la Constitución de 1988, presentando una lectura sobre el papel de la planificación y sus dimensiones técnicas, políticas y sociales. Defendemos el refuerzo de la obligatoria institucionalización de la planificación en los estudios de Derecho Administrativo, destacando su funcionalidad para asistir en el desempeño y cambio de cultura de una administración pública comprometida con la participación democrática, la eficiencia y eficacia de acciones que garanticen el acceso a los Servicios. derechos fundamentales y promoción del desarrollo. El artículo aborda, en particular, el entendimiento de que el agente público debe dar importancia a la acción de planificar observando los valores democráticos de la justicia, con la predicción de la participación en decisiones que involucren la definición de políticas públicas, costos y recursos, como así como en el control de la Administración, siendo fundamental para promover una cultura dialógica con la sociedad, apoyarse sustancialmente en el reconocimiento de la planificación, por el Derecho Administrativo, como un 
instituto para componer la descripción doctrinal y científica del régimen jurídico del Público brasileño Administración.

Palabras CLAVE: Administración pública - Planificación social - Gestión pública Agentes públicos - Políticas públicas.

ABSTRACT: This article defends the vital importance of systematic planning for the Brazilian Public Administration, especially for the new challenges posed by the SARS Covid pandemic. The analysis includes a description of the history of the use of the instrument by the Brazilian State before the 1988 Constitution, presenting a reading on the role of planning and its technical, political and social dimensions. We defend the reinforcement of the mandatory institutionalization of planning in Administrative Law studies, highlighting its functionality to assist in the performance and change of culture of a public administration committed to democratic participation, the efficiency and effectiveness of actions that guarantee access to services. fundamental rights and promotion of development. The article addresses, in particular, the understanding that the public agent must give importance to the action of planning observing the democratic values of justice, with the prediction of participation in decisions that involve the definition of public policies, costs and resources, as well as in the control of the Administration, being fundamental to promote a dialogic culture with society, to rely substantially on the recognition of planning, by Administrative Law, as an institute to compose the doctrinal and scientific description of the legal regime of the Public Brazilian Administration.

KEYWORDS: Public administration - Social planning - Public Management - Public agents - Public politics.

\section{INTRODUCCIÓN}

El Estado republicano y democrático brasileño tiene la función de cumplir con las aspiraciones que llevaron a su institucionalización, siendo una tarea permanente vinculada a su propia esencia (SARLET, 2018, p. 70) y a la garantía de los derechos fundamentales legalmente prevista. No obstante, esa tarea no se ha realizado plenamente, a pesar de que el bien común es el fundamento de la concepción estatal. El ejercicio de los derechos, por tanto, está vinculado a un conjunto de condiciones que no siempre están presentes en la vida de cada ciudadano, caracterizando una diferencia material entre las personas 
que son beneficiarias del mismo derecho. El Estado de Derecho y la igualdad no siempre van de la mano.

Por tanto, la realización de los derechos fundamentales sólo se configura con la aproximación entre gobernantes y gobernados. La materialización de la autonomía y la igualdad para todos los seres humanos está vinculada a la realización de sus necesidades, entre las primarias e intrínsecas a la condición humana y las relacionadas con el deseo de desarrollar capacidades más allá de la supervivencia cotidiana.

La mayor crisis sanitaria y pandémica del siglo, junto con la crisis política y socioeconómica, promueven la reanudación del Estado en el papel de agente activo, promotor y protector de los derechos, ofreciendo a través de los agentes públicos y del servicio público una distribución más justa de los bienes y derechos fundamentales, mientras se verifica en varias partes del mundo, un descrédito de la confianza en las instituciones democráticas y los agentes políticos. Esta paradoja plantea nuevos retos a las sociedades contemporáneas tan desiguales, situadas entre países colonizadores y colonizados. Supone un gran reto para los servidores públicos que acumulan funciones de protección y promoción de derechos en un mundo que necesita de la presencia estructural y de la ausencia física, un mundo que asimila la era digital incluso antes de garantizar una mayor eficiencia ética en el desempeño de las funciones administrativas.

La pandemia de SARS Covid, surgida en el 2019, pone radicalmente de manifiesto la fragilidad humana ante la naturaleza. Dado que es un virus con una fuerte protección sistémica y una rápida capacidad de diseminación, es el causante de la desestabilización global. Sin inversiones en ciencia y organización estatal para contener y erradicar el virus, a través de restricciones a la libertad de ir y venir, a la propiedad privada, a la producción de vacunas y a su aplicación en millones de personas en todo el mundo, las acciones contra este enemigo no se llevan a cabo de manera eficaz, devolviendo el valor del protagonismo del agente público.

Las medidas necesarias y eficientes surgen de comandos que incluyen apoyo financiero, donaciones de materiales de protección 
individual, reducción y/o amnistía de las tarifas de los servicios públicos, ampliación de las estructuras sanitarias, expansión de la red de agentes públicos, investigación científica, adquisición de insumos para la producción de vacunas y su aplicación. El protagonismo del agente público tiene un papel definitivo en las decisiones estatales y la gestión de los bienes, servidores y servicios puede generar condiciones de supervivencia tanto para la población vulnerable, como para aquellos que pueden pagar por los servicios privados. Al mismo tiempo, proteger a los funcionarios públicos de los retos que plantea la pandemia es crucial para que la sociedad avance.

El cambio necesario para modificar el escenario de desigualdad e injusticia social, que comprime la economía y devasta psicológicamente a la humanidad, no se hace sólo con el reconocimiento de derechos, sino a través del compromiso ético del agente público con la sociedad, desinflando la protección de los menos favorecidos. El desempeño de un papel más activo del Estado, que garantice la efectividad de los derechos fundamentales, que equilibre las relaciones sociales y económicas, respetando, en el caso de Brasil, lo previsto en el texto constitucional, ha adquirido un nuevo protagonismo.

Partiendo de dicha premisa, el artículo propone provocar reflexiones sobre el papel de la Administración Pública y del agente público ante la necesidad de actuar de forma planificada y la necesidad de que dicho tema sea incorporado por el Derecho Administrativo. Se refuerza así la idea de que la actuación interventora en la promoción de los derechos por parte de los poderes públicos tiene, en gran medida, impacto formal y material en la protección de la salud y la vida de los ciudadanos.

\section{PLANEACIÓN PÚBLICA BRASILEÑA Y EL PAPEL DEL AGENTE PÚBLICO}

En el caso brasileño, dirigido por las disposiciones constitucionales de 1988, el Estado tiene el deber de actuar para promover el acceso 
a los derechos fundamentales en una perspectiva ideal, de modo que el bienestar social y una calidad de vida saludable sean tratados como un fin público que debe estar al alcance de todos para garantizar su desarrollo. El papel y la condición de los agentes públicos en la garantía de esta finalidad tiene una dimensión exponencial y no se materializa sin una planeación cualificada en la cuestión social.

Brasil y su caracterización histórica, perfilada de heterogeneidad socioeconómica, desigualdad e injusticia, en varias dimensiones, exige una actuación ética, comprometida y eficiente, como la tarea de inducir, fomentar y producir las condiciones para la transformación de las estructuras económicas y sociales del país que lleven a la reducción de las desigualdades sociales y regionales y a la promoción del pleno desarrollo nacional.

Por ello, se destaca el establecimiento de los límites de la actuación estatal, prevista en el ordenamiento jurídico administrativo, para una función administrativa para la consecución de tales fines, ampliando la interpretación clásica del deber de actuar en las actividades del servicio público, poder de policía, intervención y fomento. Para que haya una concreción de los mandatos constitucionales e infra constitucionales, la planeación social y las políticas públicas son instrumentos determinantes en la actuación administrativa de promoción y protección de los derechos fundamentales.

Con el deber de una actuación estatal protagonista, la planeación y el desarrollo de las políticas públicas deben orientar la organización, la gestión, el uso y la evaluación del papel de los bienes y recursos públicos, siendo determinantes para un desempeño exitoso, que debe realizarse de forma integrada, incluyendo tanto el (re)diseño de la estructura organizativa, como la definición del perfil de la población destinataria de las acciones. El concepto de planeación democrática participativa conduce a la promoción del desarrollo humano.

La planeación es una importante herramienta que ya integra el elenco de institutos vinculados a la actuación pública, así como es identificada como principio por el Decreto-Ley n ${ }^{\circ} 200$ de 1967, 
necesitando convertirse en objeto de estudio elemental por parte del Derecho Administrativo, a fin de garantizar que la función administrativa sea ejercida dentro de los parámetros normativos y axiológicos exigidos por la Constitución de 1988.

La legislación brasileña impone una serie de acciones a ser ejecutadas por el Poder Público, partiendo de un comando para la planeación, siempre involucrando los servicios públicos, la gestión de la infraestructura del uso de los bienes, las intervenciones y el suministro de mobiliario urbano a través de planes de acción municipales, estatales, regionales y federales como referencia. La relación entre los deberes de la actuación pública y la actuación planeadora es simbiótica y se verifica en los parámetros y definiciones de directrices, metas e incluso programas que el ordenamiento jurídico impone al poder público, lo que puede verificarse fácilmente con la Ley no 101/2000, de Responsabilidad Fiscal.

La exigencia de la planeación estatal se justifica en la razón de ser del propio Estado. Aunque puede ser objeto de muchas discusiones científicas sobre el asunto, es un hecho que la previsión de un Estado republicano y democrático como el brasileño, autoriza la acción administrativa para actuar a través de los instrumentos y dentro de los límites que demarcan su creación y mantenimiento en que, la planeación es un instrumento vital para lograr este objetivo (Marrara, 2011, p. 02).

La historia de la planeación en Brasil tiene fuertes vínculos con la actuación del Estado económico y se ha desarrollado en la intimidad de una gestión pública de perfil no democrático, siendo importante rescatar dicha memoria (REzende, 2009, p. 03). Asimismo, la noción de planeación siempre ha estado vinculada al tema de las reformas administrativas en Brasil, aunque no haya sido indicada como referencia principal en la reciente propuesta de Enmienda a la Constitución n. 32/2020.

La referencia al Plan SALTE, un plan de inversiones en salud, alimentación, transporte y energía, un programa de gasto público en 
sectores considerados prioritarios, de 1950 a 1954, es un punto importante de la actuación de la planeación en Brasil en la $2^{\text {a }}$ posguerra, sirviendo de refuerzo a la interpretación del como afrontar lo que el país padece actualmente (MATos, 2002, p. 29). Incluso con poca o ninguna transparencia, el proyecto de planeación propuso una agenda para el crecimiento de Brasil que logró reunir a diferentes grupos sociales, de diversos intereses, en torno a las promesas de que el país avanzaría 50 años en cinco y sería posible una nueva sociedad, reparando las desigualdades históricas, a través de los cambios (ScHwarCZ, Starling, 2014, p. 416-417).

En cierta medida, Brasil ha avanzado en la comprensión de la necesidad de invertir en la planeación. Sin embargo, el impacto en la situación social no fue lo suficientemente significativo como para cambiar el escenario que todavía se conoce en la actualidad. Brasil sigue siendo desigual, especialmente en las medidas que pueden modificar la educación, la salud, la vivienda y otras condiciones de vida para los sectores más desfavorecidos de la población (Almeida, 2004, p. 03).

La creación del Sistema Federal de Planeación, a través del Decreto $n^{\circ} 71.353 / 1972$, formalizó un proceso de planeación federal con algunos objetivos que destacaron su importancia en la esfera pública, como las funciones de: coordinar la elaboración de planes y programas y controlar su ejecución, asegurar la aplicación de criterios técnicos en la elección de prioridades, modernizar la administración pública y establecer un flujo permanente de información. El órgano federal que centralizaba todas las actividades pasó a ser responsable de la articulación de las acciones bajo la responsabilidad de los Estados y Municipios, directamente a través de sus respectivos órganos centrales de planeación, e indirectamente a través de la relación de las agencias sectoriales federales con sus homólogas estatales y municipales (REZENDE, 2009, p. 07-08).

La planeación tiene una larga y tortuosa historia dentro de la Administración brasileña, siendo visto como un objeto de estudio 
sólo de la ciencia de la administración, todavía fuertemente ligado a las cuestiones económicas y urbanas, sin la necesaria articulación y coordinación con las funciones administrativas.

Se rescata aquí la defensa de su entendimiento en la medida de las distintas funciones que ejerce el Estado. En primer lugar, debe (re)conocerse como una etapa fundamental, como exigen las leyes brasileñas, y así desarrollarse de forma sistematizada, aunque cada acción pública requiera especialidad, siendo conducida a partir de un conjunto de directrices políticas, sociales y económicas que dialogan entre sí. Su uso permite la racionalidad en la predicción de los comportamientos administrativos, las decisiones públicas y la elección de las inversiones financieras, organizando la formulación de los objetivos y la definición de los medios de acción coordinados a ser más fácil de visualizar y controlar (GRAU, 2010, p. 309-310).

La planeación también es un proceso político. Puede conducir a la consecución de la mejora de algo, en este caso el uso racional, funcional y agradable de los recursos, así como servir de instrumento para lograr la mayor eficacia posible en la realización de acciones ejecutadas con este fin (BAPTISTA, 2013, p. 17). Sin embargo, es una actividad que implica la técnica y la política, centrada en el presente y orientada hacia el futuro, buscando la sostenibilidad en la previsión y el tratamiento del espacio público y sus actores, así como en la evolución de las relaciones sociales, culturales, económicas.

Para la realización de programas de acción, elegidos en el núcleo de las políticas públicas, sería necesario el reconocimiento de algunas áreas del Derecho, como el Derecho Administrativo, reconociendo la importancia y la necesidad de estudiar y apoyar de forma cualificada a los servidores para la planeación, que tiene elementalmente la función de aumentar la capacidad de eficacia de las decisiones públicas (MotтA, 1991, p. 19), identificando los problemas y las dificultades frente a las situaciones que reciben la afluencia de variadas condiciones socioeconómicas, ambientales y también políticas, nacionales e internacionales. 
Brasil ha acumulado la experiencia de la planeación a lo largo de décadas, en diferentes líneas de acción y gobierno. Necesita capacitar a sus agentes para asumir tal técnica con las orientaciones dadas por la Constitución de 1988, desde la perspectiva del Estado Democrático y Social, para promover el acceso a los derechos sociales, permitiendo también la posibilidad de control y evaluación crítica sobre la actividad administrativa del Estado, que instrumentalizada por la planeación social sería más eficaz.

\section{ADMINISTRACIÓN PÚBLICA, PLANEACIÓN SOCIA Y DERECHOS FUNDAMENTALES}

El cumplimiento de las previsiones del Estado Constitucional para la realización de la igualdad material, la protección y la promoción de los derechos sigue siendo el mayor desafío de la administración pública brasileña. Ya sea por la complejidad que caracteriza a la actuación del ejecutivo en un país con una peculiar configuración federalista (Salgado, Gabardo, 2009) y grandes desigualdades socioeconómicas, o por la existencia de un núcleo de fuerzas políticas y económicas que defienden la presencia de un Estado no intervencionista, el hecho es que la Constitución demarcó el modelo de Estado brasileño, definiendo su función de inducir el desarrollo humano como uno de los objetivos estatales.

En un Estado liberal, la actividad del ejecutivo está destinada a promover la libertad, garantizar la seguridad y la soberanía nacional (GABARdo, 2003, p. 116). Formalmente, según una lectura precisa de la Constitución de 1988, esto no sería posible en el Brasil contemporáneo, aunque, bajo el manto de las "crisis", se intente legitimar un intento de reducir la acción del Estado. El capítulo constitucional, titulado "Da Ordem Social”, por sí mismo, ya describe las funciones y, por lo tanto, intuye la estructura necesaria para el Estado brasileño en el que la planeación es una condición para la eficiencia y la eficacia. 
En la actual descripción constitucional, las previsiones de comportamiento de la Administración difieren en gran medida de la conformación liberal, ya que las disposiciones jurídicas, localizadas a partir de los objetivos de la República, prevén la construcción de una sociedad libre, justa y solidaria; la garantía del desarrollo nacional; la erradicación de la pobreza y la marginación y la reducción de las desigualdades sociales y regionales, así como la promoción del bien de todos, sin prejuicios de origen, raza, sexo, color, edad y cualquier otra forma de discriminación (BrasiL, 2007, p. 03). Todavía más, la mención formal y descriptiva de la participación social es una marca del Estado democrático; representativo y participativo son características elementales de la democracia brasileña.

La Constitución de 1988 trata de valores y bienes que deben protegerse y hacerse accesibles con la participación concreta e interventora del Estado, en la que la garantía del desarrollo nacional pasa, particularmente, por su buen desempeño como actor e inductor socioeconómico (Nohara, 2012, p. 07).

En el caso brasileño, la relevancia de la presencia estatal se encuentra con la importancia que el texto constitucional otorga a los derechos fundamentales. Por lo tanto, para la realización del Estado Social Democrático se requiere de las diversas dependencias y entidades públicas, en todos los ámbitos federativos, un compromiso para mejorar la vida de la población a través de diferentes formas de actuación, que van más allá de la obediencia al mandato legal como resultado, para exigir la realización de este como un objetivo mayor a ser logrado. La planeación es una herramienta natural para una acción eficaz, pero debe ser elegida condición necesaria para una acción eficiente.

La adopción de modelos de gestión que aumenten la capacidad de la Administración Pública para promover el bienestar social, atendiendo con eficiencia y efectividad las nuevas/viejas y las crecientes demandas de la sociedad brasileña, requiere la asunción definitiva de la actividad de planeación en diálogo con los destinatarios de las acciones públicas. 
Las "lagunas" existentes en la red de prestación de servicios públicos y el reducido número de funcionarios tienen una relación directa con el número de personas que se encuentran fuera de las áreas de cobertura potencial. La respuesta a esta falla es un deber, el de cumplir con el precepto constitucional, responsabilidad del "Sistema Único de Saúde (SUS)". La garantía a todos los ciudadanos brasileños del acceso a los servicios de salud, con cobertura de sus necesidades asistenciales e igualdad de trato a las personas con necesidades diversas, requiere agentes cualificados y entornos seguros y estructurados para el desempeño de estas funciones. El cumplimiento de este precepto se hace aún más fundamental en un escenario de agravamiento epidemiológico, como es el contexto de la pandemia de Covid-19.

La buena administración es realizada por el agente público cuando el cumplimiento de sus deberes se da para atender los intereses y las necesidades de los ciudadanos, ofreciéndoles los servicios públicos de manera isonómica, eficiente y eficaz, obedeciendo a los principios y las normas que rigen el comportamiento público, asegurándole el acceso, la participación dialógica y el trato cordial, entre otras garantías que sólo pueden ser efectivas desde la perspectiva de la reflexión y la acción planificada. Esto es lo que puede llamarse buena administración (Rodríguez Arana-Muñoz, 2012, p. 171-174) un derecho ciudadano resultante de la concepción político-jurídica del Estado brasileño.

A pesar de toda la innovación constitucional en materia de derechos fundamentales, así como de la descripción de algunos instrumentos que garantizan su materialización, cabe destacar que su aplicación no ha sido lineal ni pacífica, con avances y retrocesos marcados por las oscilaciones políticas, económicas y administrativas que son utilizadas, cada una a su manera, como justificaciones para una redefinición ilegítima del papel del Estado (UgÁ, 1989). En los últimos años, los ataques al texto constitucional para debilitar al agente público han sido voraces e incluso en tiempos de pandemia sanitaria, de lo único que se habla en la máxima instancia del poder ejecutivo federal es de inclinar la máquina administrativa y reducir 
el papel de la administración mediante el discurso de la austeridad y la ineficiencia. ${ }^{1}$

Es función de la Administración ofrecer oportunidades de acceso a los derechos, además de protegerlos. Sin una planeación sistematizada y procedimental, ¿cómo podría hacerse? La protección como única forma de acción administrativa no avanza en la reducción de las desigualdades, en contra de las políticas públicas inclusivas y de los servicios públicos eficaces que son fundamentales, incluso para la promoción y el mantenimiento del desarrollo socioeconómico (MENEZES, Simpson, 2015).

Se destaca la configuración de los derechos y su incorporación por la Constitución de 1988, especialmente los derechos económicos y sociales fundamentales, con la institución de atribuciones al Estado para su realización, reforzando la intención de promover, finalmente, la igualdad material (НАснем, 2014, p. 64). La dignidad de la persona humana abarca tanto la plena capacidad de la persona para disfrutar de sus derechos civiles y políticos, como, entre otros, los derechos económicos, sociales y culturales, dado el peso de la capacidad socioeconómica en los llamados derechos civiles, destacando que la integralidad del ser humano corresponde definitivamente con la integralidad de sus derechos (Piovesan, 1998, p. 54). Sin la función planificadora del Estado, no hay forma de lograr esa integralidad en el estado actual

\footnotetext{
"A postura do presidente no encontro foi elogiada por empresários. "Foi uma conversa boa, eu gostei, me deu tranquilidade", definiu Rubens Menin, controlador de MRV, Banco Inter e da rede de televisão CNN. Segundo o empresário, Bolsonaro também se comprometeu com a austeridade fiscal e com as reformas, que são outras demandas do setor produtivo." Disponible en:https://www.em.com.br/app/noticia/economia/2021/04/08/ internas_economia,1254881/em-jantar-com-empresarios-bolsonaro-promete-acelerarvacinacao.shtml. Acceso en abril de 2021. "O CNS (Conselho Nacional de Saúde) elaborou uma carta aberta em que afirma que o Orçamento destinado ao financiamento do SUS (Sistema Único de Saúde) para o ano de 2021 é incompatível com os seus custos mínimos, principalmente no contexto da crise da Covid-19." Disponible en: https:// amazonasatual.com.br/conselho-nacional-de-saude-diz-que-orcamento-para-o-susprioriza-austeridade-fiscal-a-vida-do-cidadao/. Acceso en abril de 2021.
} 
de las cosas. La planeación debe considerarse como un elemento, no sólo de control de la actuación administrativa, sino controlable en el sentido de las opciones que debe tomar el gestor público.

En consecuencia, la Constitución de 1988 diseñó un Estado que necesariamente ejecuta e implementa las políticas públicas. La actuación administrativa, a partir de los mandatos constitucionales, debe actuar de forma intervencionista en los ámbitos económico y social, para provocar las transformaciones estructurales necesarias. Así, la Administración Pública debe actuar de forma amplia y específica, basándose en datos concretos, interpretaciones técnicas y políticas, definición de estrategias y estudio de costes y recursos, participación social, enfocándose en la promoción de la justicia social. La identificación de las demandas de interés social debe incluir a los ciudadanos como protagonistas, interlocutores y destinatarios reales de la distribución justa de los bienes y servicios administrativos. La planeación debe utilizarse como una herramienta que promueva el diálogo entre los poderes públicos y la sociedad, en los distintos niveles de fragmentación que ésta presenta.

Para cumplir con tales expectativas, la Administración Pública necesita abandonar de una vez por todas el sello no sólo del patrimonialismo, el autoritarismo y la ineficiencia, sino también del perfil de "bombero", siempre apagando incendios sin estructurarse para evitarlos (Bresser Pereira, Spink, 2006). La reproducción de un modelo burocrático que no planifica o planea articuladamente, colocando al agente público estable en el centro de las decisiones, no respeta las directrices constitucionales está desconectado de la racionalidad constitucional que adoptó el Estado brasileño democrático y republicano, lo que lo hará sufrir, internamente, de un desorden ideológico bipolar (PinTO Ferreira, 1989, p. 574).

La definición de los objetivos constitucionales pretende orientar la acción administrativa, donde la planeación está visceralmente ligada al cumplimiento de dichas tareas. Si bien es necesario considerar las disputas políticas, las legítimas, como elementos reales y necesarios en 
una democracia, no hay manera de justificar el retroceso y la parálisis en la acción administrativa que transforma la vida del individuo social y económicamente frágil. No hay manera de reconocer formalmente la presencia del instituto de la planeación y no incorporarlo a los estudios y la doctrina dentro del derecho administrativo.

El tema se refuerza a partir del entendimiento de que la vida cotidiana del ciudadano es una interacción, directa o indirecta, con el Poder Público. Históricamente, la Administración Pública brasileña actúa de forma centrada en sus elementos instrumentales, guiada por métodos y procesos formales de actuación con escasa o nula flexibilidad para la audiencia de los ciudadanos que son los destinatarios de sus acciones (REZENDE, 2009, p. 06-09). Es necesario un comportamiento diferente, más eficaz que permita, incluso, la participación equitativa en la discusión y definición de los recursos a ser aplicados, inclusive para evitar desviaciones por corrupción (Melo, 2010, p. 59).

La planeación como elemento material de la acción administrativa está siendo defendida como un mandato para el agente probo, que actúa con impersonalidad y eficiencia, en una sociedad contemporánea y democrática, que, en el ejercicio de su función elabora y organiza estrategias para hacer frente a los problemas sociales, construye metas y define recursos para, a través de las políticas públicas y la prestación de servicios, permitir y garantizar el ejercicio de los derechos fundamentales. La planeación es vista aquí como una acción que orienta a la Administración hacia los objetivos de bienestar social a ser alcanzados, bajo la perspectiva de una actuación controlada. La planeación es un instituto que crea procedimientos, etapas de actuación que hacen la Administración más transparente, el servidor más seguro y que favorece el diálogo y el control.

Aún sobre el papel del Estado en la promoción del acceso a los derechos fundamentales, es necesario destacar que el régimen jurídico al que se somete la actuación de la Administración Pública no indica descriptivamente la presencia de la planeación como un comando para el agente público. Bajo la perspectiva jurídica, que define el 
comportamiento estatal, la indicación normativa de la necesidad de la planeación se produce en diferentes capítulos que tratan sobre la Administración Pública o sobre los derechos fundamentales, estando presente, especialmente en el capítulo del orden económico, en el que su referencia se realiza de forma llamativa, indicando incluso su obligatoriedad.

La reflexión sugiere que el instituto de planeación sea observado por el Derecho Administrativo, como un elemento a ser fortalecido para su cumplimiento obligatorio, promoviendo su definitiva internalización en el núcleo de las estructuras de la Administración Pública en los diversos niveles de gobierno, entrelazando la propia actuación administrativa, la que se produce en la gestión del territorio de la ciudad. Se trata de defender la planeación como un mando que articula los aspectos administrativos, sociales, físico-territoriales, ecológicos y, también, económicos, induciendo la participación social (co)responsable en la administración de los intereses públicos.

El reconocimiento de la planeación como una importante herramienta de gestión requiere un cambio de mentalidad de los agentes y gestores públicos, así como la conciencia de los ciudadanos sobre su presencia e importancia en la realización y definición de las opciones públicas. Es necesario inducir un comportamiento institucional prospectivo y preventivo, consciente de los deberes de obediencia a los parámetros del estado democrático y social constitucionalizado que eligió la promoción pública de la participación social y el acceso a los derechos fundamentales como forma de lograr el bienestar social, como su objetivo más importante.

\section{A MODO DE CONSIDERACIONES}

Se propone una reflexión sobre el papel desempeñado por los juristas en la comprensión del ordenamiento jurídico, comprometidos con el cambio de conductas administrativas ineficaces y 
poco comprometidas con la finalidad del Estado, así como en la construcción de nuevos paradigmas para el Derecho Administrativo, que al interpretar las normas constitucionales e infraconstitucionales ligadas a los valores de justicia, ética y ciudadanía, puedan fortalecer la presencia de la planeación como instituto normativo fundamental, provocando su observancia con mayor firmeza dentro de las gestiones político-institucionales, político-administrativas y político-sociales.

Los agentes públicos que cumplen las tareas de responsabilidad del Estado no pueden prescindir de la planeación, como proceso institucionalizado, obligatorio para quienes ejercen la función pública ejecutiva (Bucci, 2013, p. 38). Existen numerosos textos normativos que prevén dicha actuación, sin embargo, la cultura sigue siendo el maquillaje o la insuficiencia en la actuación planeada.

Aún todavía, es importante destacar que la planeación no podría prescindir de la participación ciudadana en su definición y control de la acción y los resultados a ser alcanzados. Si la actuación pública tiene el deber de promover el interés público, una acción sistemáticamente planificada garantiza una mayor posibilidad de alcanzar los deberes públicos, así como su control puede hacerse de forma más efectiva. Se trata de argumentos racionales, que siguen encontrando resistencia en el ámbito de las gestiones, ya sea por razones o motivos políticos, por una cultura administrativa autoritaria o por la incapacidad estructural de emprender la planeación. Con el fortalecimiento de la doctrina administrativa, reconociendo el papel de la planeación como un instituto importante a ser estudiado, sería posible cambiar tales escenarios y apoyar al agente público para más oportunidades de calificación, mejora de las condiciones de trabajo y seguridad en el desempeño de sus actividades.

Sin planeación, el Estado-administración no puede identificar, definir, aplicar y sostener recursos humanos y materiales en las demandas reprimidas, así como, en el caso específico de la cuestión de la salud global, no construye instrumentos y acciones para inducir su superación. Para garantizar el desarrollo humano, adoptar políticas 
públicas sostenibles, modificar la cultura administrativa, alimentar la información y la comunicación con la sociedad, desde la perspectiva de la gestión y el control, es que la planeación se presente como un elemento contemporáneo decisivo para la eficiencia del Estado en la promoción del bienestar social y la calidad de vida saludable.

El derecho administrativo necesita potenciar el instituto de la planeación social al lado de las políticas públicas, traduciéndolo bajo la perspectiva técnica jurídica, reforzando su función prospectiva de ayuda a la transformación de la realidad existente; su papel en la vida funcional de los agentes públicos, definiendo los caminos y objetivos específicos de la acción pública.

Si bien es posible dar cuenta de avances significativos en la acción pública contemporánea con la implementación de políticas públicas sociales (CAsimiro, Sousa, 2020), sistemas de evaluación y gestión, definición de instrumentos de participación e importantes marcos legales para la consolidación de los derechos fundamentales, la impronta de la desigualdad es muy fuerte, y la llegada del COVID 19 ha profundizado esta condición, lo que solicita aún más la presencia de la planeación como elemento importante de la acción pública (CARLEIAL, 2013). La Administración Pública necesita mejorar la forma en que lleva a cabo sus acciones, que no se producen rápidamente, no sólo por el perfil brasileño ya destacado, sino también porque las acciones del Estado para promover el desarrollo deben seguir un paradigma democrático que a menudo se aleja de los dictados de la eficiencia (Mariano, Maia, 2020).

La planeación, también como instrumento político, compromete al agente público a proteger el interés público de la irracionalidad, del automatismo sesgado y personal, de la corrupción. Garantiza el debate y la transparencia en las decisiones y los reajustes necesarios, provoca el dinamismo dadas las definiciones objetivas de acción que comienzan, a solicitar, también, otros mecanismos como los de control del cumplimiento de metas y objetivos.

Su institucionalización material es esencial para el Estado Social Democrático de Derecho, al ser reconocido como un instrumento-medio por 
el cual la acción administrativa puede dar vida a un diseño funcional en el que se establecen las pautas espaciales, temporales y de contenido que permiten al poder público cumplir con lo establecido en el texto normativo constitucional e infraconstitucional, y a los ciudadanos a tener satisfechas parte de sus necesidades (CARDOso JúnIOR, 2013).

La democracia brasileña se inserta en un contexto de gran complejidad, en el que ya no existe una solución única que pueda presentarse en una disposición simple para la comprensión de todos. Parece necesario establecer claramente un comportamiento estatal que pueda definir las agendas políticas para dar respuestas a las demandas sociales firmemente comprometidas con el desarrollo humano y la planeación asiste en este papel, y debe incorporarse como un instituto básico a cobrar desde el gestor público.

La actuación de la Administración Pública en el actual Estado brasileño debe establecer objetivos y metas para cambiar la realidad actual, la actuación pública democrática que debe implicar la planeación y la participación social en la definición de las inversiones en infraestructura y servicios públicos, la red de protección de los derechos fundamentales, la configuración de la eficacia y la eficiencia prometida y esperada. Para ello, se entiende necesario que los estudios sobre el régimen jurídico de la Administración Pública involucren el instituto de la planeación desde la perspectiva social y el papel que juega en una gestión eficiente vinculada a los valores de justicia social y bienestar equitativo, para diversos escenarios.

El acceso a los derechos fundamentales se dará más efectivamente a partir de un conjunto de acciones político-administrativas comprometidas con los valores jurídicos que fueron elegidos explícitamente por la Constitución brasileña de 1988. Dentro de esta perspectiva, la planeación y la actividad de planeación son obligaciones que deben cumplir los poderes públicos, construyendo bases firmes para una estructura que sea capaz de mantener la estabilidad socioeconómica, humana y sostenible de las ciudades, en un proceso constante y progresivo de desarrollo (MATA, 2019). Si la planeación es 
un proceso que sugiere una administración flexible al prever diversos escenarios para la consecución de sus objetivos ante un panorama de profunda desigualdad social, es también un instrumento de condicionamiento y control integrador de las actividades, que impone el compromiso del derecho administrativo con su comprensión y fortalecimiento doctrinal.

Desde la perspectiva del derecho administrativo positivo y de la ciencia del derecho administrativo, ante las exigencias de la nueva normalidad, pandémica y post-pandémica, se requiere su fortalecimiento tanto en el ámbito de la acción prospectiva y preventiva de la Administración Pública, como componente sustancial para, con transparencia y diálogo público, conducir acciones precisas para equilibrar las relaciones sociales y económicas, el bienestar social urbano y la protección de los recursos naturales, como elemento objetivo a considerar en el contexto del control de las acciones administrativas.

\section{REFERENCIAS BIBLIOGRÁFICAS}

ALMEIDA, Paulo Roberto de. A experiência brasileira em planejamento econômico: uma síntese histórica. p.3, 2004. In http://www. pralmeida.org/02Publicacoes/00Publicacoes.html Acceso en 20 de marzo de 2021.

BAPTISTA, Myrian Veras. Planejamento social: intencionalidade e instrumentação. São Paulo: Veras Editora, 2013.

BRASIL. Constituição da República Federativa do Brasil: promulgada em 5 de outubro de 1988. Colaboração de Antonio Luiz de Toledo Pinto, Márcia Cristina Vaz dos Santos Windt e Lívia Céspedes. São Paulo: Saraiva, 2007.

BRESSER PEREIRA, Luiz Carlos; SPINK, Peter. Reforma do Estado e administração pública gerencial. Rio de Janeiro: Fundação Getúlio Vargas, 2006.

BUCCI, Maria Paula Dallari. Fundamentos para uma teoria jurídica das políticas públicas. São Paulo: Saraiva. 2013. 
CARDOSO JÚNIOR, J. Celso. Planejamento governamental, orçamentação e administração pública no Brasil: alavancas para o desenvolvimento sustentável. In: Estado, planejamento e administração pública no Brasil. Instituto Municipal de Administração Pública. Curitiba: IMAP, 2013.

CARLEIAL, Liana Maria da Frota. O desafio da reinvenção do Estado no Brasil. In: Estado, planejamento e administração pública no Brasil. Instituto Municipal de Administração Pública. Curitiba: IMAP, 2013

CASIMIRO, Ligia Maria Silva Melo de; SOUSA, Thanderson Pereira de. A tutela do direito à saúde pela Administração Pública: delineando o conceito de tutela administrativa sanitária. Revista de Investigações Constitucionais, Curitiba, vol. 7, n. 2, p. 601-629, mayo/ago. 2020. DOI: 10.5380/rinc.v7i2.71320.

GABARDO, Emerson. Eficiência e Legitimidade do Estado: uma análise das estruturas simbólicas do Direito Público. Barueri: Manole, 2003.

GRAU, Eros Roberto. A ordem econômica na Constituição de 1988. São Paulo: Malheiros, 2010.

HACHEM, Daniel Wunder. Tutela administrativa efetiva dos direitos fundamentais sociais: por uma implementação espontânea, integral e igualitária. Tesis (Doctorado) - Universidade Federal do Paraná, Setor de Ciências Jurídicas, Programa de Pós-graduação em Direito, Curitiba, 2014. MARIANO, Cynara Monteiro. MAIA, Isabelly Cysne Augusto. As Narrativas Pós-Modernas e o Paradigma da Eficiência: a democracia participativa na trilha dos tijolos amarelos. Revista Seqüência - Estudos Jurídicos e Políticos, Florianópolis, v. 41 n. 86, p. 63-88, nov.2020. http://doi. org/10.5007/2177-7055.2020v41n86p63.

MARRARA, Thiago. Atividade de planejamento na administração pública: o papel e o conteúdo das normas previstas no anteprojeto da nova lei de organização administrativa. Revista Eletrônica de Direito do Estado n ${ }^{\circ} 27$ - julio/agosto/septiembre. Salvador, 2011.

MATA, Ismael. La planificación como instrumento de Control. In RODRIGUEZ-ARANA, Jaime... et al. (Orgs). Control Administrativo de la actividad de la administración. Vol. 1. XVIII Foro Iberamericano de Derecho Administrativo. São Paulo, 2019 
MATOS, Patrícia de Oliveira. Análise dos planos de desenvolvimento elaborados no Brasil após o II PND. Dissertação apresentada no Programa de Pós Graduação da Escola Superior de Agricultura Luiz de Queiroz. Piracicaba, 2002.

MELO, Lígia. Direito à Moradia no Brasil - Política Urbana e acesso por meio da regularização fundiária. Belo Horizonte: Fórum, 2010.

MENEZES, Francisco; SIMPSON, Mariana Dias. Universalização dos serviços para universalização da cidadania. Revista Política Social e Desenvolvimento. Cidadania Social: acesso a serviços como direito. año 3 diciembre, p.10, 2015. http://plataformapoliticasocial.com.br/ universalizacao-dos-servicos-publicos-para-universalizacao-da-cidadania/ Acceso en 20 de marzo de 2021.

MOTTA, Paulo Roberto. Gerenciando o futuro: a conquista da visão estratégica. Rio de Janeiro: Record, 1991.

MUÑOZ, Jaime Rodríguer-Arana. Direito fundamental à boa Administração Pública. Tradução Daniel Wunder Hachem. Belo Horizonte: Fórum, 2012.

NOHARA, Irene. Reforma Administrativa e Burocracia: impacto da eficiência na configuração do direito administrativo brasileiro. São Paulo: Atlas, 2012.

PINTO FERREIRA, Luiz. Comentários à Constituição Brasileira. São Paulo: Saraiva, vo. 1, 1989.

PIOVESAN, Flávia. A Proteção Internacional Dos Direitos Econômicos, Sociais e Culturais. In: Temas de Direitos Humanos, (co-autoras: Alessandra Passos Gotti e Janaína Senne Martins), In: Temas de Direitos Humanos, $1^{\text {a }}$ ed., Max Limonad, 1998.

REZENDE, Fernando. Planejamento no Brasil: auge, declínio e caminhos para a reconstrução. CEPAL, comissão econômica para a américa latina e o caribe, Junio 2009, p. 3.

SALGADO, Eneida Desireé; GABARDO, Emerson. A competência legislativa municipal para a inovação da linha substitutiva em caso de impedimento ou vacância do prefeito municipal. Revista Paraná Eleitoral 071. Disponible en: http://www.tre-pr.jus.br/arquivos/tre-pr-revista-parana-eleitoral-n071-2009-eneida-desiree-salgado-e-emerson-gabardo/view. Acceso en 05 de marzo de 2021 
SARLET, Ingo Wolfgang. A Eficácia dos Direitos Fundamentais. Rev., atual. e ampl. Porto Alegre: Livraria do Advogado Editora, 2018.

SCHWARCZ, Lilia Mortiz; STARLING, Heloisa Murgel. Brasil: uma biografia. São Paulo: Companhia das Letras, 2014.

UGÁ, Maria Alícia D. Crise econômica e políticas sociais: elementos para discussão. Cadernos de Saúde Pública, v. 5, n. 3, p. 305-335, 1989.

\section{LÍGIA MARIA SILVA MELO DE CASIMIRO}

Profesora de Derecho Administrativo de la Universidad Federal de Ceará (Fortaleza-CE, Brasil). Doctorado en Derecho Económico y Desarrollo por la Pontificia Universidad Católica de Paraná. Maestría en Derecho del Estado de la Pontificia Universidad Católica de São Paulo.

Dirección profesional: Faculdad de Derecho, R. Meton de Alencar, S/n - Centro, Fortaleza - CE, 60035-160, Brasil.

ORCID ID: https://orcid.org/0000-0001-7987-4381

Correo electrónico: meloligia@gmail.com

\section{ÁLVARO SANCHEZ BRAVO}

Doctor en Derecho - Universidad de Sevilla, España. Profesor de la Facultad de Derecho de la Universidad de Sevilla, España.

Dirección profesional: Calle San Fernando, 4, 41004 Sevilla, España. ORCID ID: https://orcid.org/0000-0002-8610-3240

Correo electrónico: elialva@us.es

Recibió: 30/03/2021

Aceptado: 25/06/2021 